\title{
Obtaining Shear-Wave Velocity Structure from Broadband Seismic and Strong-Motion Recordings
}

\author{
Zhenming Wang \\ Kentucky Geological Survey \\ University of Kentucky \\ Lexington, Kentucky, USA \\ zmwang@uky.edu
}

\author{
Mianshui Rong \\ Institute of Crustal Dynamics \\ China Earthquake Administration \\ Beijing, China
}

\author{
Seth Carpenter \\ Kentucky Geological Survey \\ University of Kentucky \\ Lexington, Kentucky, USA \\ Seth.carpenter@uky.edu
}

\begin{abstract}
Horizontal-to-vertical spectral ratio (HVSR) analysis and inversion were applied to $S$-waves from a large database of broadband seismic and strong-motion recordings. The S-wave HVSR, in comparison with ambient noise spectral ratio, contains much information on the shear-wave velocity structure. In other words, inversion of S-wave HVSR provides a detailed shear-wave velocity structure, which can be better used for nonlinear site-response analysis. The results showed that the HVSR of the S-wave can be used to improve or constrain the soil shear-wave velocity profile obtained from other methods.
\end{abstract}

Keywords-shear-wave velocity; horizontal-to-vertical spectral ratio (HVSR); broadband seismic recordings; strong-motion recordings

\section{INTRODUCTION}

Near-surface shear-wave velocity structure is of engineering interest. For example, in current engineering practice, the site coefficient for seismic design is determined by the time-weighted average of shear-wave velocity for the top $30 \mathrm{~m}$ of soils. There are several noninvasive methods, including surface refraction/reflection, spectral analysis surface waves (SASW), multichannel analysis of surface waves (MASW), ambient noise spectral ratio, and random microtremor (REMi), for characterizing shear-wave velocity structure. These methods have many advantages, such as costeffectiveness and being environmentally friendly; they also have some disadvantages, such as nonuniqueness and other physical limitations. Thus, how to obtain a reliable shear-wave velocity structure from these methods is still being researched.

Recent large-scale deployments of broadband and strong-motion stations in the United States (i.e., EarthScope Project: www.earthscope.org) and China (i.e., China Strong Motion Networks: 222.222.119.9; China Seismic Array: www.chinaarray.org) have provided a large database and opportunity for research on reliable characterization of shearwave velocity. We used strong-motion recordings from the China Strong Motion Networks in China and broadband seismic recordings from the EarthScope Project in the central United States to derive shear-wave velocity profiles with the horizontal-to-vertical spectral ratio (HVSR) method.

\section{HORIZONTAL-TO-VERTICAL SPECTRAL RATIO ANALYSIS AND INVERSION}

Since it was introduced in 1989 by Nakamura ${ }^{[6]}$, the HVSR method has been widely used for estimating shear-wave velocity of near-surface soils from ambient-noise/microtremor measurements. For example, several studies have derived shear-wave velocity profiles from ambient-noise/microtremor HVSR analyses ${ }^{[1][8]}$. The HVSR method has also been applied to strong motions from earthquakes ${ }^{[4][5][7]}$. For example, Lermo and Chavez-Garcia ${ }^{[4]}$ found that the HVSR of the S-wave part of the strong-motion record can be used to estimate the empirical transfer function.

As shown by Kawase and others ${ }^{[3]}$, HVSR is related to shear-wave velocity structure. The observed HVSR's of the Swave can be used to derive shear-wave velocity structure by inversion. A combination of the simple and the guided Monte Carlo search can be used for the inversion ${ }^{[2]}$.

$$
\text { misfit }=\sum\left\{\left[\operatorname{HVSR}_{\mathrm{OBS}}\left(f_{i}\right)-H V S R_{\text {THE }}\left(f_{i}\right)\right] W_{i}\right\}^{2}
$$

where indices OBS and THE stand for the observed and theoretical HVSR of the S-wave, and $\mathrm{Wi}$ is the weight defined by:

$$
W_{i}=\left[\operatorname{HVSR}_{\mathrm{OBS}}\left(f_{i}\right)\right]^{E}, E \geq 0 .
$$

This inversion algorithm can be applied to the S-wave HVSR of broadband seismic and strong-motion recordings to obtain shear-wave velocity structure ${ }^{[7]}$.

\section{DATA AND RESUlts}

The China Strong Motion Network Center (CSMNC) (www.csmnc.net) operates the National Strong-Motion Observation Network System of China (NSMONS), which consists of more than 1,700 stations throughout China. NSMONS has recorded more than 200 earthquakes with $\mathrm{M}>$ 4.7, including the 12 May 2008 Ms 8.0 Wenchuan and 20 April 2013 Ms 7.0 Lushan earthquakes. The Ms 8.0 Wenchuan earthquake occurred along the central and northern segments of the Longmen Shan Fault in Sichuan Province, western China. More than 1,400 strong-motion components from the Wenchuan earthquake's mainshock and more than 20,000 strong-motion components from aftershocks were 
recorded by NSMONS. The Lushan earthquake occurred on the southern segment of the Longmen Shan Fault. Ground motions from the mainshock of the Lushan earthquake were observed at 92 stations, and more than 1,000 strong-motion components from aftershocks were recorded by NSMONS. The strong-motion records from 21 stations located within 300 $\mathrm{km}$ of the Longmen Shan Fault were used for S-wave HVSR analysis and inversion (Fig. 1) (Rong and others, 2016). Figure 2 shows three components of acceleration time histories recorded at station 51SFB from the 2013 Lushan mainshock (Ms7.0) and S-wave windows. Figure 3 shows the observed HVSR and theoretical HVSR of the S-wave (E-W component) from aftershocks (small events) for the initial and inverted shear-wave velocity models (Table I) at station 51SFB.

Table I. INITIAL AND INVERTED SOIL STRUCTURES AT STATION 51SFB.

\begin{tabular}{ccccccc}
\hline \multicolumn{3}{c}{ Initial Model } & \multicolumn{5}{c}{ Inverted Model } \\
\hline No. & $\begin{array}{c}T h \\
(\mathrm{~m})\end{array}$ & $\begin{array}{c}V_{\mathrm{s}} \\
(\mathrm{m} / \mathrm{s})\end{array}$ & $\begin{array}{c}\rho \\
\left(\mathrm{g} / \mathrm{m}^{3}\right)\end{array}$ & $T h(\mathrm{~m})$ & $\begin{array}{c}V_{\mathrm{s}} \\
(\mathrm{m} / \mathrm{s})\end{array}$ & $\rho\left(\mathrm{g} / \mathrm{m}^{3}\right)$ \\
\hline 1 & 3.3 & 136 & 1.8 & 1.4 & 42 & 1.7 \\
2 & 5.1 & 263 & 2.3 & 6.4 & 283 & 2.6 \\
3 & 0.6 & 150 & 2.0 & 0.4 & 124 & 2.0 \\
4 & 3.0 & 452 & 2.5 & 0.9 & 521 & 2.4 \\
5 & 3.2 & 548 & 2.6 & Half & 548 & 2.6 \\
& & & & scpace & & \\
\hline
\end{tabular}

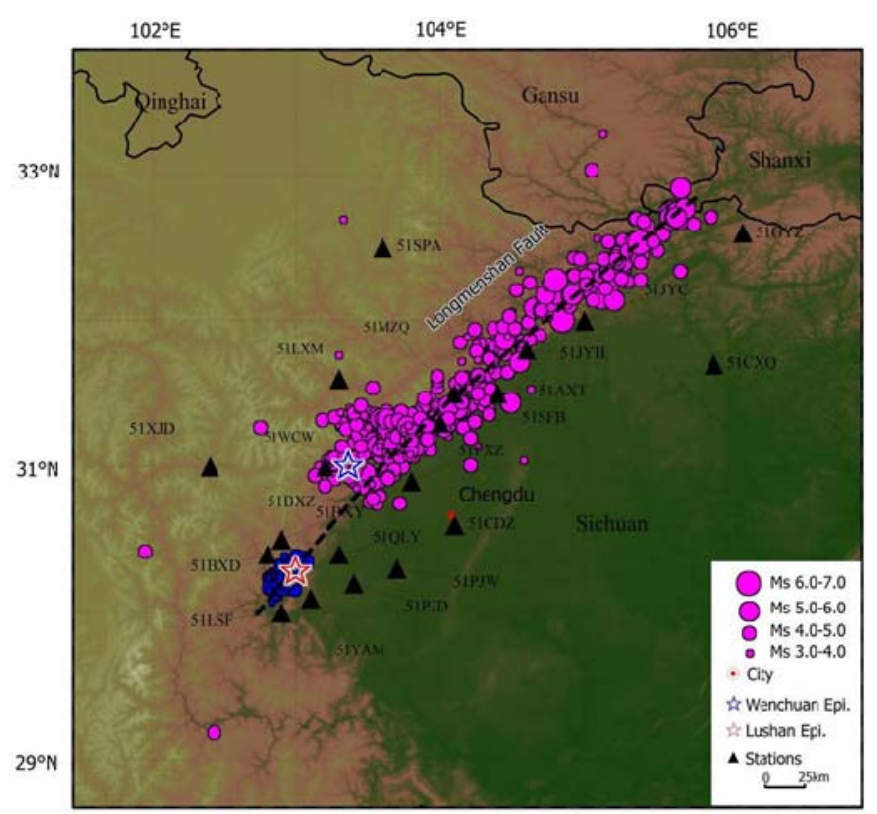

Fig. 1. Locations of the mainshock and aftershock of the 2008 Wenchuan and 2013 Lushan earthquakes and strong-motion stations within $300 \mathrm{~km}$ of the Longmen Shan Fault.
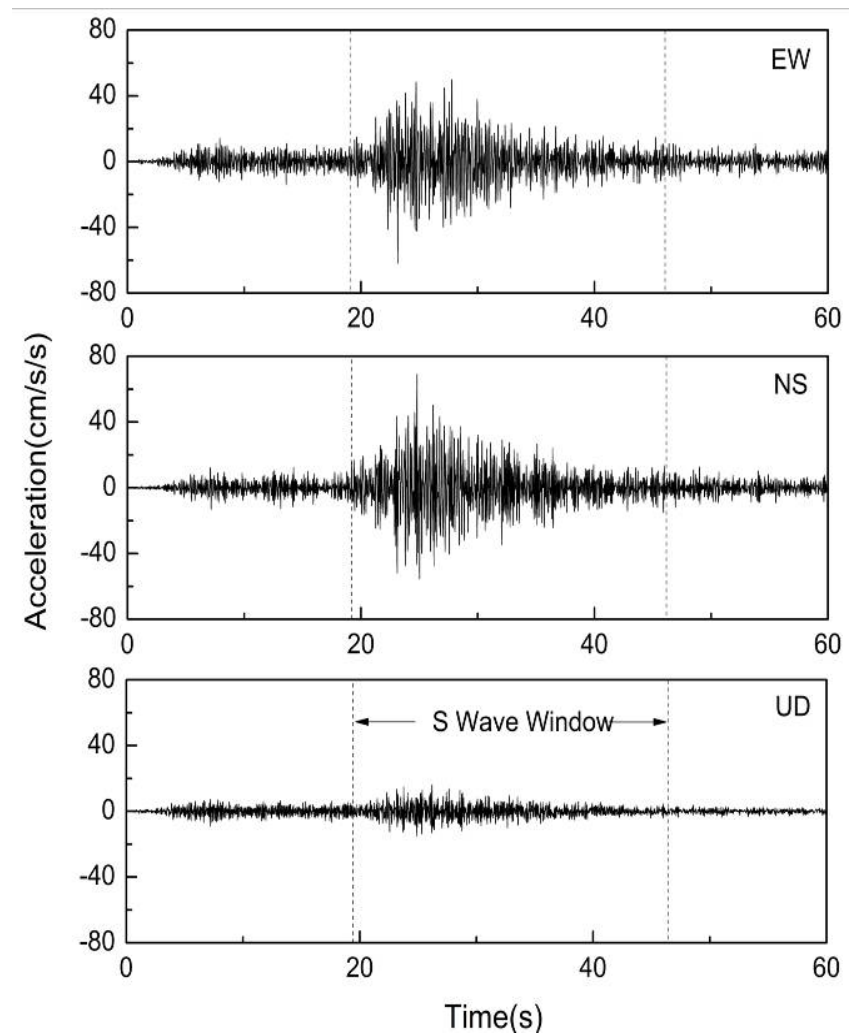

Fig. 2. Three components of acceleration time histories recorded at station 51SFB from the 2013 Lushan mainshock (Ms7.0).

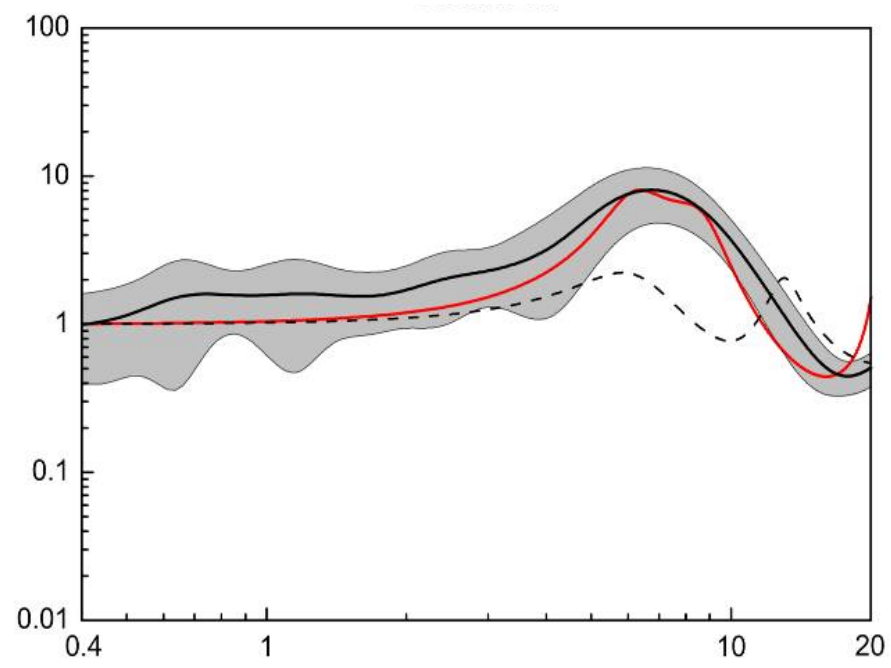

Fig. 3. Comparison of the observed HVSR and theoretical HVSR for the initial and inverted shear-wave velocity models at station 51SFB. The bold black line is the average of observed S-waves from aftershocks (small events), the shaded area represents its 95\% confidence limit, the red line is the best-fit model, and the dashed line is the initial model.

Fig. 4 shows locations of selected EarthScope USArray Transportable Array and strong motion stations in and near the New Madrid (NMSZ) and Wabash Valley Seismic Zones (WVSZ) in the central United States. All the data for TA and strong motion stations can be obtained through IRIS's BREQ_FAST data service at //ds.iris.edu/ds/nodes/dmc. Figure 5 shows waveforms from a magnitude 3.9 earthquake 
recorded at station U44A and S-wave windows. Figure 6 shows the HVSR's for ambient noise (a) and the S-wave (b) from the magnitude 3.9 earthquake at station U44A. The ambient-noise HVSR was determined by averaging horizontal- (square root of the sum of the squares of both orthogonal horizontal components) and vertical-component amplitude spectra calculated from 10-minute-long, 50\% overlapping windows of $6 \mathrm{hr}$. of continuous waveform data, and determining the ratio of the averages. As shown in Figure 3 , the ambient-noise HVSR is simple: only one dominant peak at about $0.3 \mathrm{~Hz}$, whereas the S-wave HVSR is more complex: several peaks, including the one at about $0.3 \mathrm{~Hz}$. In other words, the S-wave HVSR can provide more detailed information on shear-wave velocity structure than the ambient-noise HVSR can. Thus, the inversion of the S-wave HVSR can provide a more detailed shear-wave velocity structure.

\section{IV.SUMMARY}

A large database of broadband seismic and strong-motion recordings, S-waves in particular, in the United States and China provides an opportunity for research on shear-wave velocity structure using HVSR analysis and inversion. The Swave HVSR contains much information on shear-wave velocity structure. The inversion of the S-wave HVSR can provide a more detailed shear-wave velocity structure. Rong and others ${ }^{[7]}$ used the inverted shear-wave velocity structure for a nonlinear site response analysis with a 1-D equivalentlinear site-response model, and showed that the spectral ratios (i.e., transfer functions) from 1-D analysis agree quite well with the HVSR's in terms of the predominant frequency and amplitude at similar peak ground acceleration levels. This suggests that the HVSR's of S-waves can be used to improve or constrain the soil profile, which would be better for nonlinear site- response analysis.

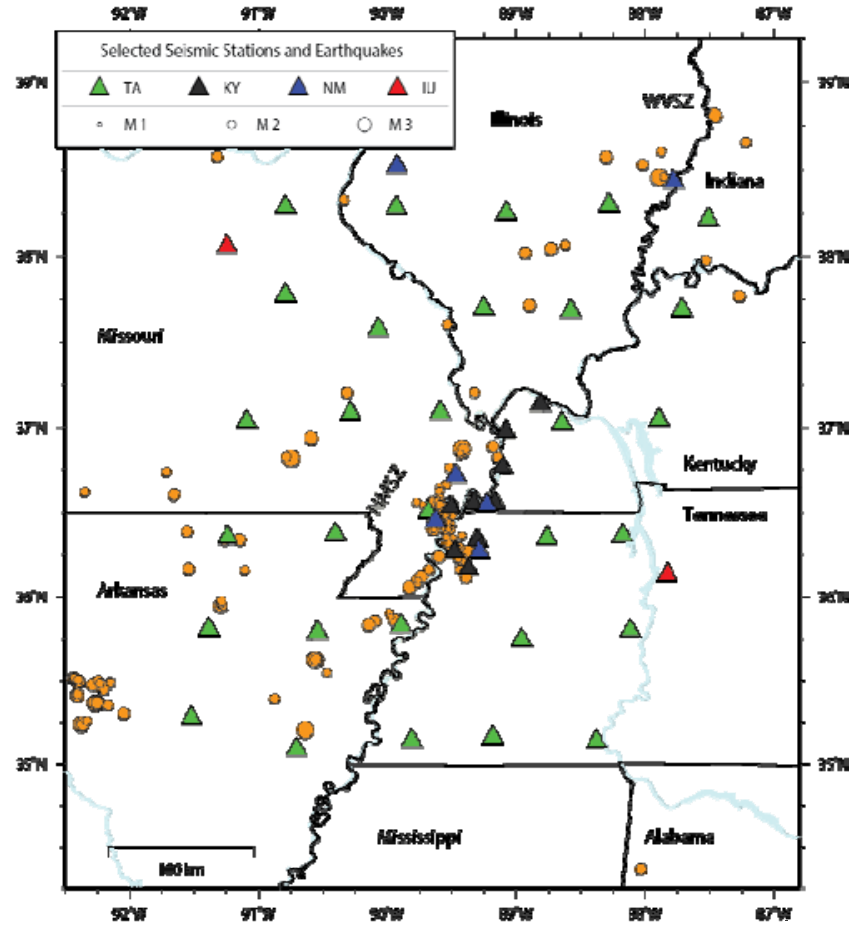

Fig. 4. Locations of selected EarthScope USArray Transportable Array and strong motion stations in and near the New Madrid (NMSZ) and Wabash Valley Seismic Zones (WVSZ). Stations are colored by network: TA = USArray Transportable Array, KY = University of Kentucky, NM = New Madrid, IU = IRIS/USGS GSN. Earthquakes from 2011/07 through 2013/07 are also shown.

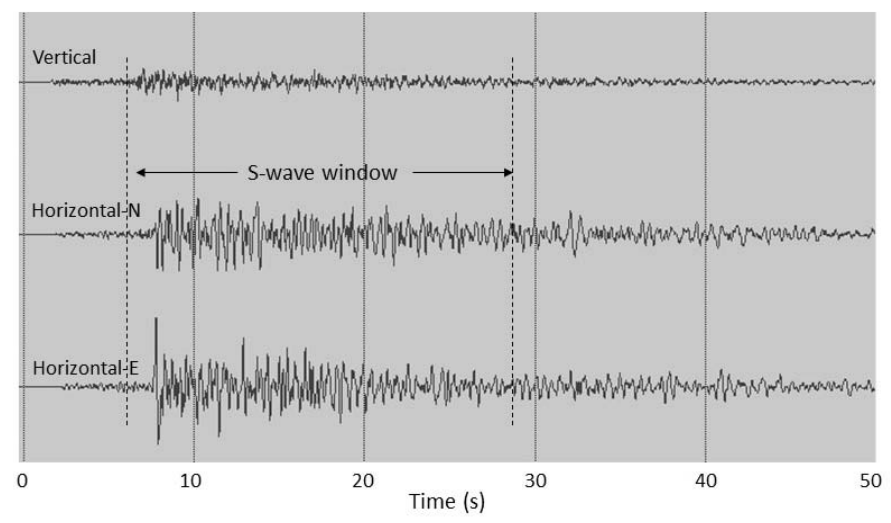

Fig. 5. Vertical- and horizontal-component seismograms from an M 3.9 earthquake on February 21, 2012, at station U44A. 


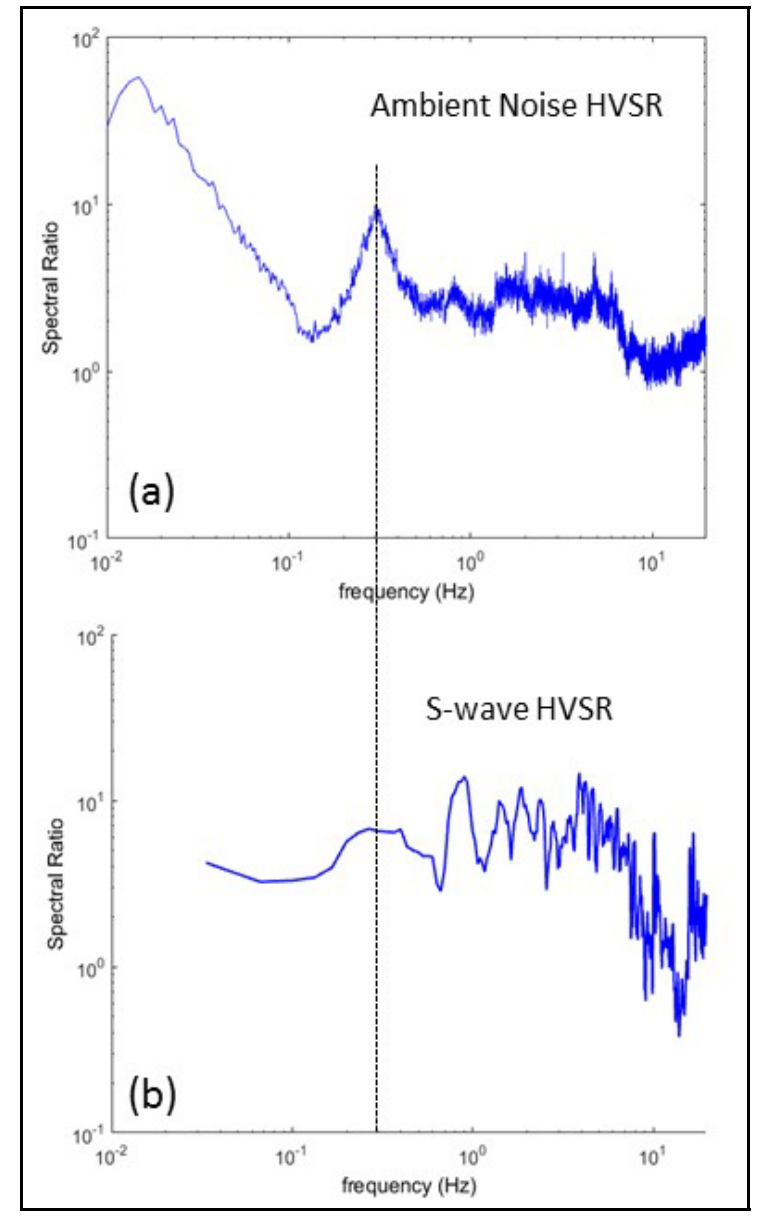

Fig. 6. HVSR's of the ambient noise (a) and S-wave (b) from an M 3.9 earthquake on February 21, 2012, at station U44A.

\section{ACKNOWLEDGMENT}

We would like to thank The China Strong Motion Network Center and IRIS Data Management Center for providing the strong ground motion records used in this study. We also thank Meg Smath for editorial help.

\section{REFERENCES}

[1] Arai, H., and Tokimatsu, K., "S-Wave velocity profiling by inversion of microtremor H/V spectrum,” Bulletin of the Seismological Society of America, vol. 94, pp. 53-63, 2004.

[2] Herak, M., "Model HVSR-A Matlab tool to model horizontal-to-vertical spectral ratio of ambient noise," Computer \& Geosciences, vol. 34, pp. 1514-1526, 2008.

[3] Kawase, H., Sánchez-Sesma, F.J., and Matsushima, S., “The optimal use of horizontal-to-vertical spectral ratios of earthquake motions for velocity inversions based on diffuse field theory for plane waves," Bulletin of the Seismological Society of America, vol. 101, pp. 20012004, 2011.

[4] Lermo, J., and Chavez-Garcia, F., "Site effect evaluation using spectral ratios with only one station,” Bulletin of the Seismological Society of America, vol. 83, pp. 1574-1594, 1993.

[5] Nagashima, F., Matsushima, S., Kawase, H., Sánchez-Sesma, F.J., Hayakawa, T., Satoh, T., and Oshima, M., “Application of vorizontal-tovertical spectral ratios of earthquake ground motions to identify subsurface structures at and around the K-NET site in Tohoku, Japan," Bulletin of the Seismological Society of America, vol. 104, pp. 22882302, 2014.

[6] Nakamura, Y., “A method for dynamic characteristics estimation of subsurface using microtremor on ground surface,” Quarterly Report of Railway Technical Research Institute, vol. 30, pp. 25-33, 1989.

[7] Rong, M., Wang, Z., Woolery, E.W., Lu, Y., Li, X., and Li, S., "Nonlinear site response from the strong ground-motion recordings in western China,” Soil Dynamics and Earthquake Engineering, vol. 82, pp. 99-110, 2016.

[8] Woolery, E.W., and Street, R., "3D near-surface soil response from H/V ambient-noise ratios,” Soil Dynamics and Earthquake Engineering, vol. 22, pp. 865-876, 2002. 